\title{
Application of alanine-scanning to determination amino acids essential for peptide adsorption at the solid/solution interface and binding to the receptor: surface-enhanced Raman/infrared spectroscopy vs. bioactivity assays
}

Edyta Proniewicz ${ }^{a}$, Grzegorz Burnat ${ }^{b}$, Helena Domin ${ }^{b}$, Izabela Małuch ${ }^{c}$, Marta Makowska $^{c}$, Adam Prahl ${ }^{c}$

aaculty of Foundry Engineering, AGH University of Science and Technology, 30-059 Krakow, Poland

${ }^{\mathrm{b}}$ Maj Institute of Pharmacology, Polish Academy of Sciences, Department of Neurobiology, 12 Smętna 12, 31-343 Kraków, Poland

${ }^{\mathrm{c}}$ Faculty of Chemistry, University of Gdansk, Wita Stwosza 63, 80-308, Gdansk, Poland

*corresponding author: proniewi@agh.edu.pl 


\section{Analytical data of synthesized peptides}

pGlu-GIn-Arg-Leu-Gly-Asn-Gln-Trp-Ala-Val-Gly-His-Leu-Met-NH2, $\quad$ BN

$[\mathrm{M}+\mathrm{H}]^{+}$calculated 1619.871 , found 1619.666<smiles>CSCCC(NC(=O)C(CC(C)C)NC(=O)C(Cc1c[nH]cn1)NC(=O)CNC(=O)C(NC(=O)[C@H](C)NC(=O)[C@H](Cc1c[nH]c2ccccc12)NC(=O)[C@H](CCC(N)=O)NC(=O)[C@H](CC(N)=O)NC(=O)CNC(=O)[C@H](CC(C)C)NC(=O)[C@H](CCCNC(=N)N)NC(=O)[C@H](CCC(N)=O)NC(=O)C1CCC(=O)N1)C(C)C)C(N)=O</smiles>

Ala-GIn-Trp-Ala-Val-Gly-His-Leu-Met-NH2, $\quad\left[\mathrm{Ala}^{1}\right] \mathrm{BN}^{6-14}$

$[\mathrm{M}+\mathrm{H}]^{+}$calculated 1011.214, found 1011.431

mAU<smiles>CSCC[C@H](NC(=O)[C@H](CC(C)C)NC(=O)[C@H](Cc1c[nH]cn1)NC(=O)CNC(=O)[C@@H](NC(=O)[C@H](C)NC(=O)[C@H](Cc1c[nH]c2ccccc12)NC(=O)[C@H](CCC(N)=O)NC(=O)[C@H](C)N)C(C)C)C(N)=O</smiles>
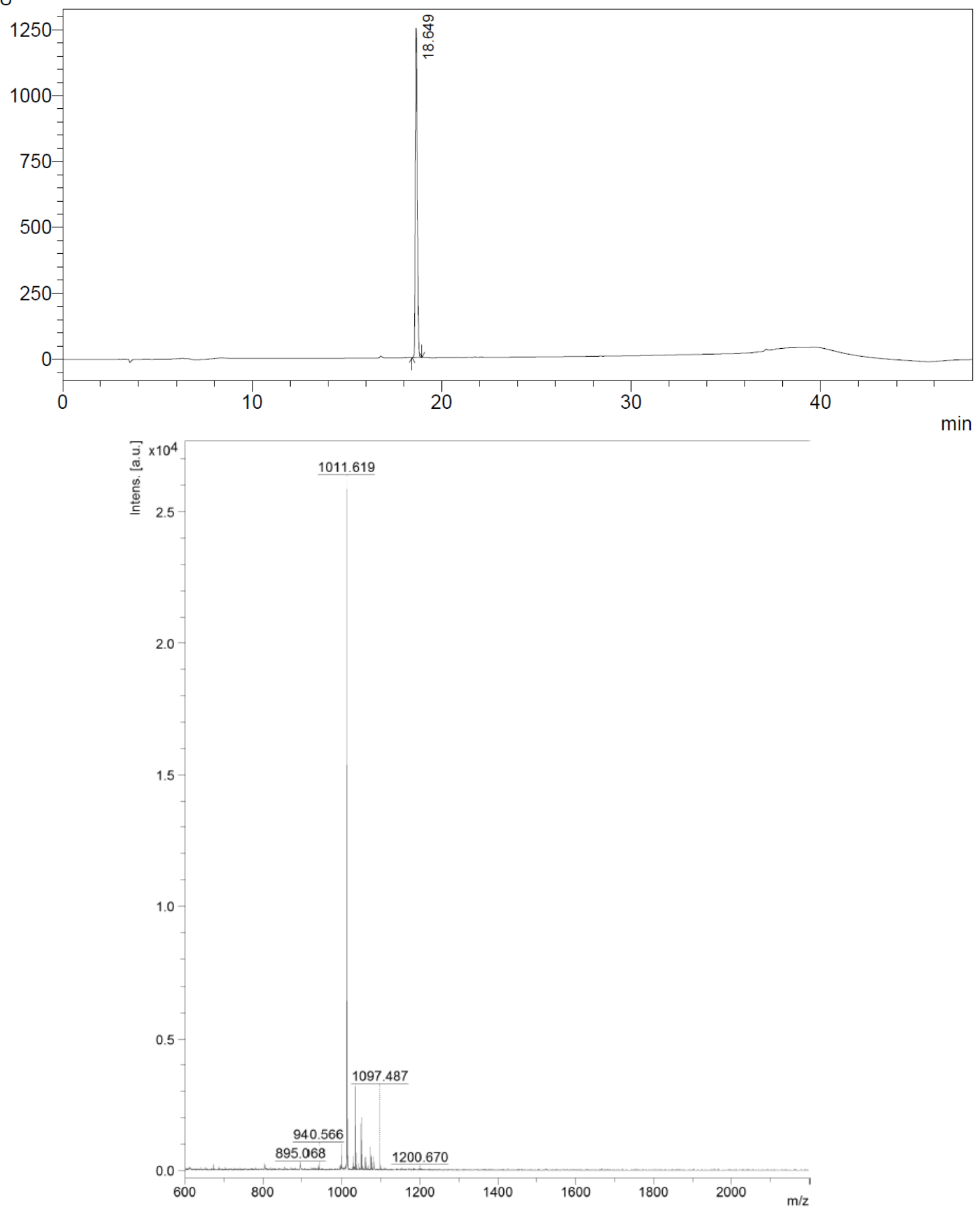
Asn-Ala-Trp-Ala-Val-Gly-His-Leu-Met- $\mathrm{NH}_{2}, \quad\left[\mathrm{Ala}^{2}\right] \mathrm{BN}^{6-14}$

$[\mathrm{M}+\mathrm{H}]^{+}$calculated 997.187 , found 997.445

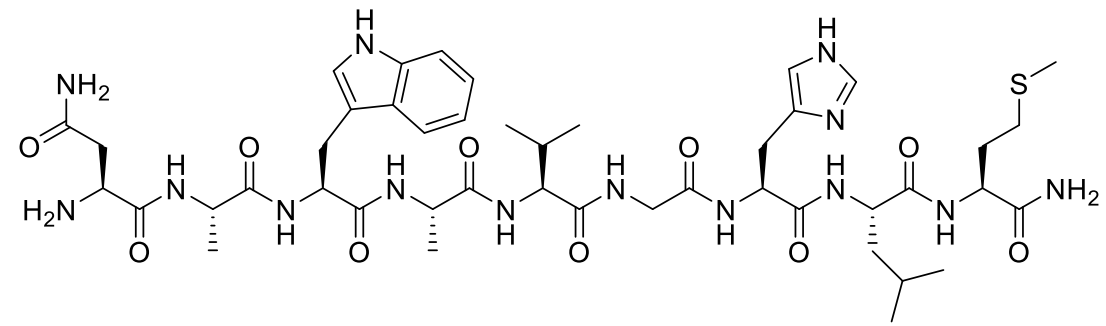

mAU
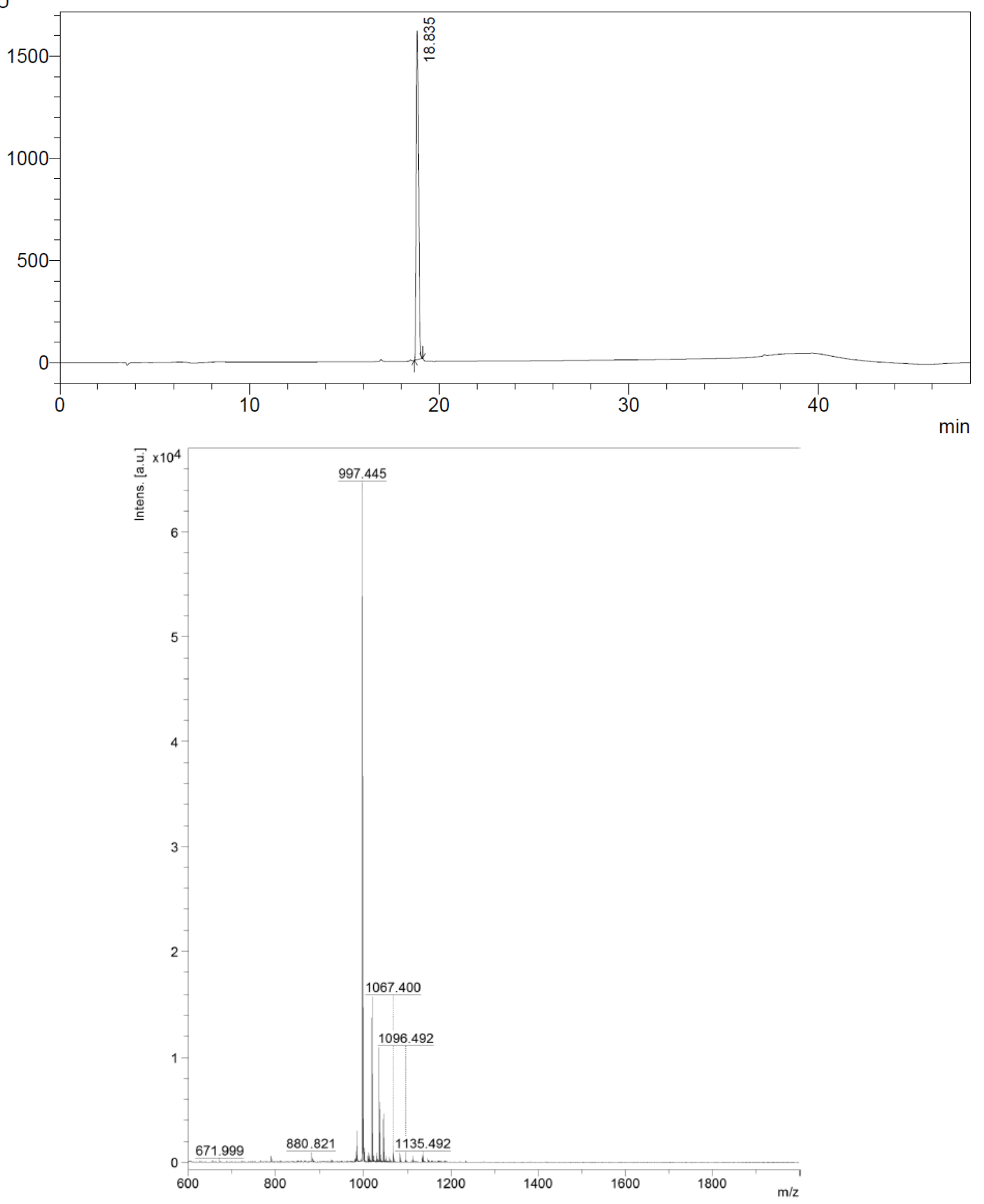
Asn-GIn-Ala-Ala-Val-Gly-His-Leu-Met-NH2, $\quad\left[\mathrm{Ala}^{3}\right] \mathrm{BN}^{6-14}$

$[\mathrm{M}+\mathrm{H}]^{+}$calculated 939.104, found 939.420

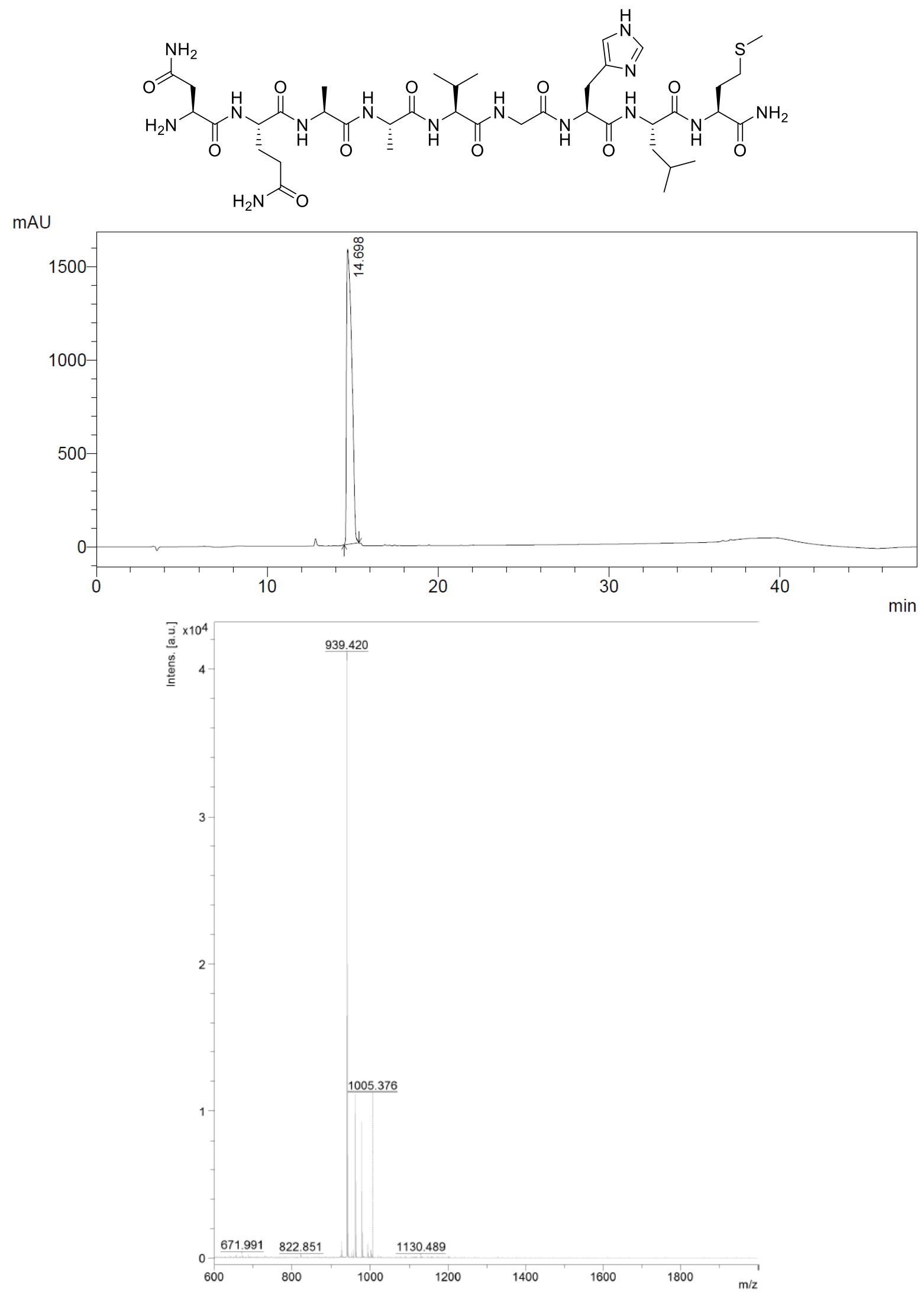




\section{Asn-Gln-Trp-Ala-Ala-Gly-His-Leu-Met-NH2 , [Ala ${ }^{5} \mathrm{BN}^{6-14}$}

$[\mathrm{M}+\mathrm{H}]^{+}$calculated 1026.185 , found 1026.442

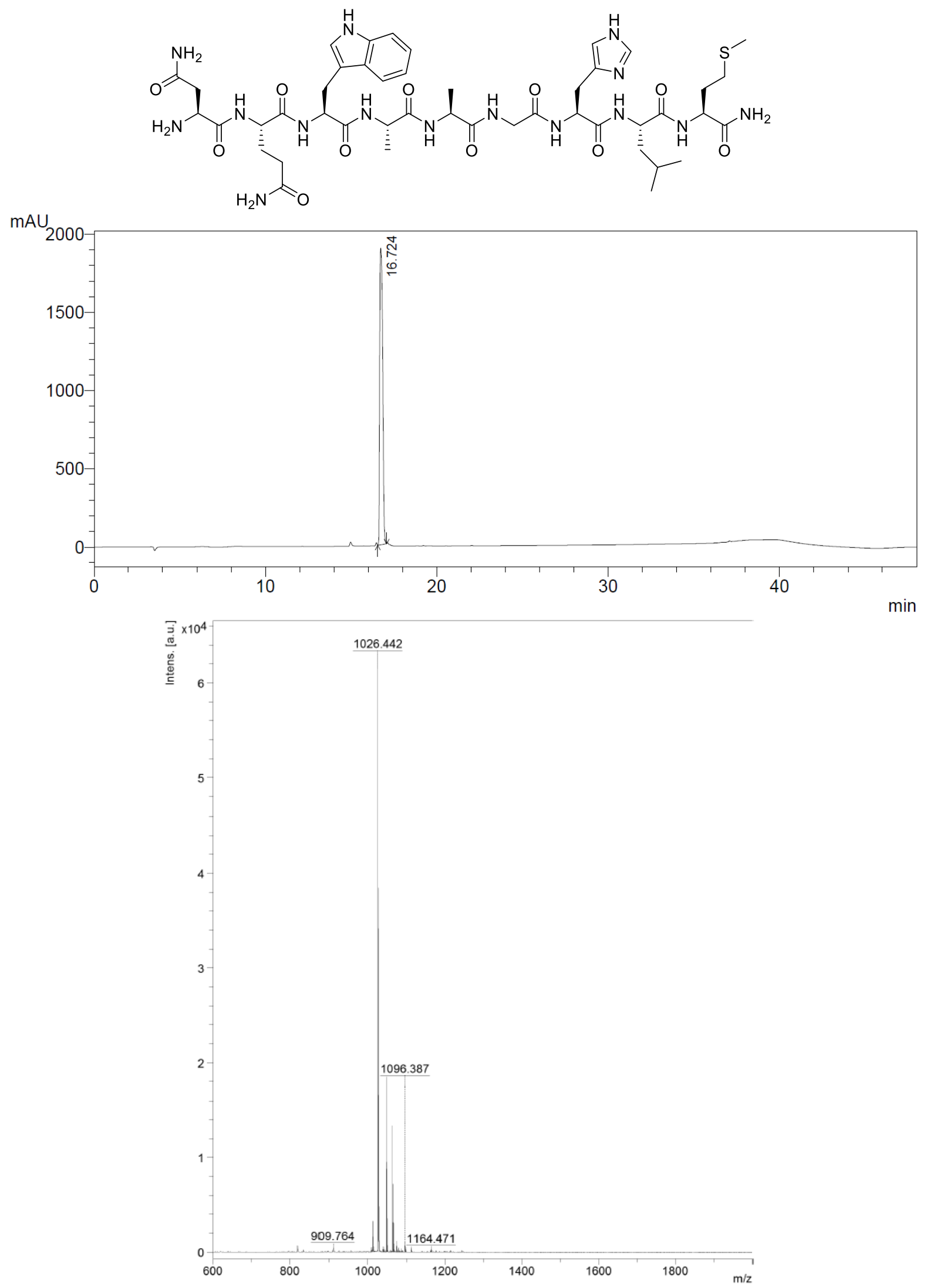


Asn-GIn-Trp-Ala-Val-Ala-His-Leu-Met-NH2,

$\left[\mathrm{Ala}^{6}\right] \mathrm{BN}^{6-14}$

$[\mathrm{M}+\mathrm{H}]^{+}$calculated 1068.266 , found 1068.489

Asn-GIn-Trp-Ala-Val-Gly-Ala-Leu-Met-NH2, $\quad\left[\mathrm{Ala}^{7}\right] \mathrm{BN}^{6-14}$

$[\mathrm{M}+\mathrm{Na}]^{+}$calculated 1010.485 , found 1010.429

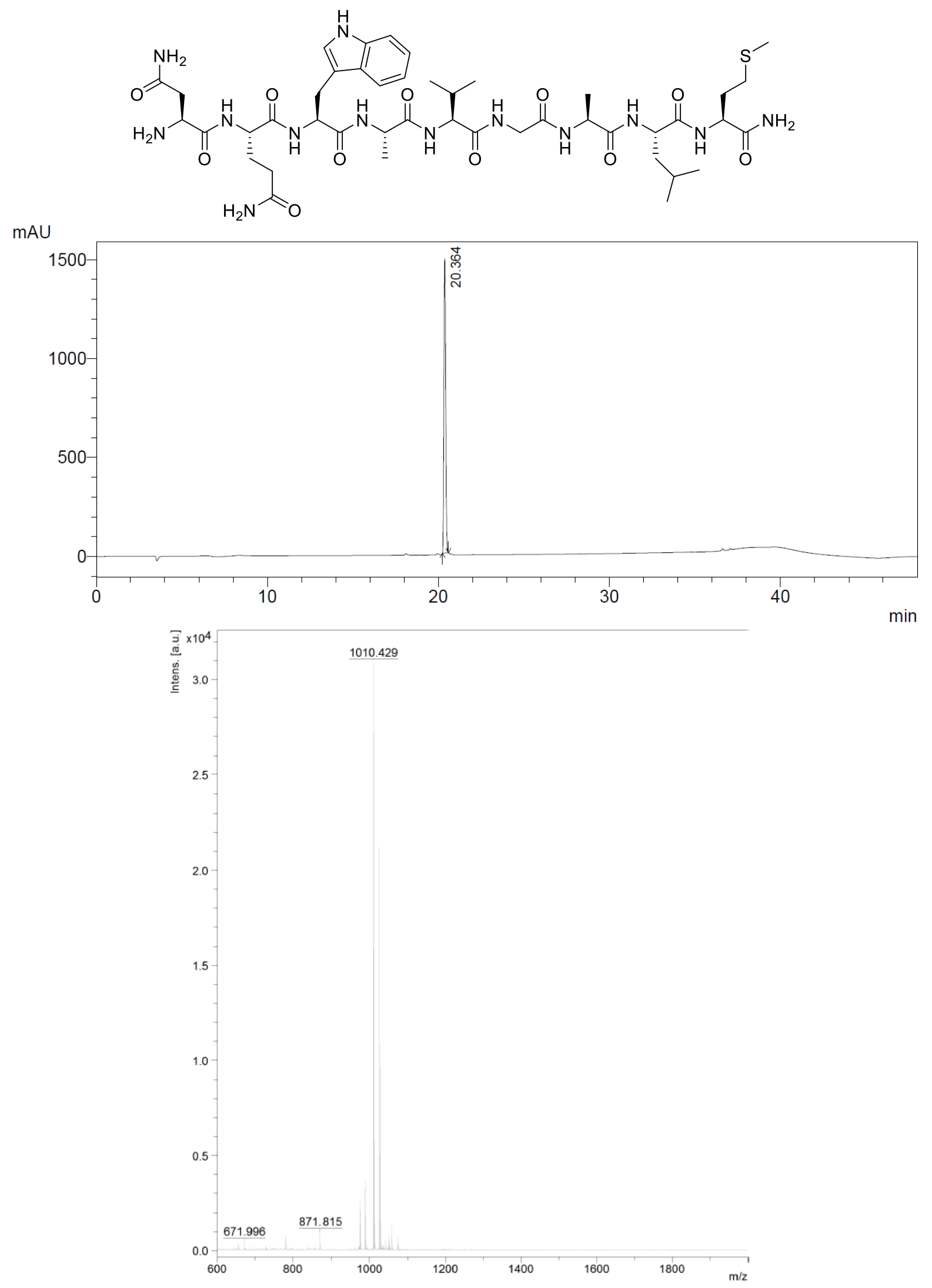


Asn-Gln-Trp-Ala-Val-Gly-His-Ala-Met-NH2, $\quad\left[\mathrm{Ala}^{8}\right] \mathrm{BN}^{6-14}$

$[\mathrm{M}+\mathrm{H}]^{+}$calculated 1012.158, found 1012.419

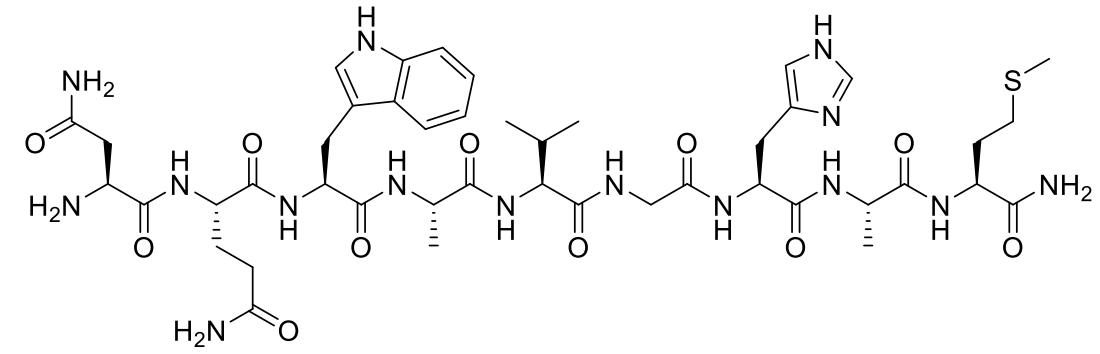

mAU
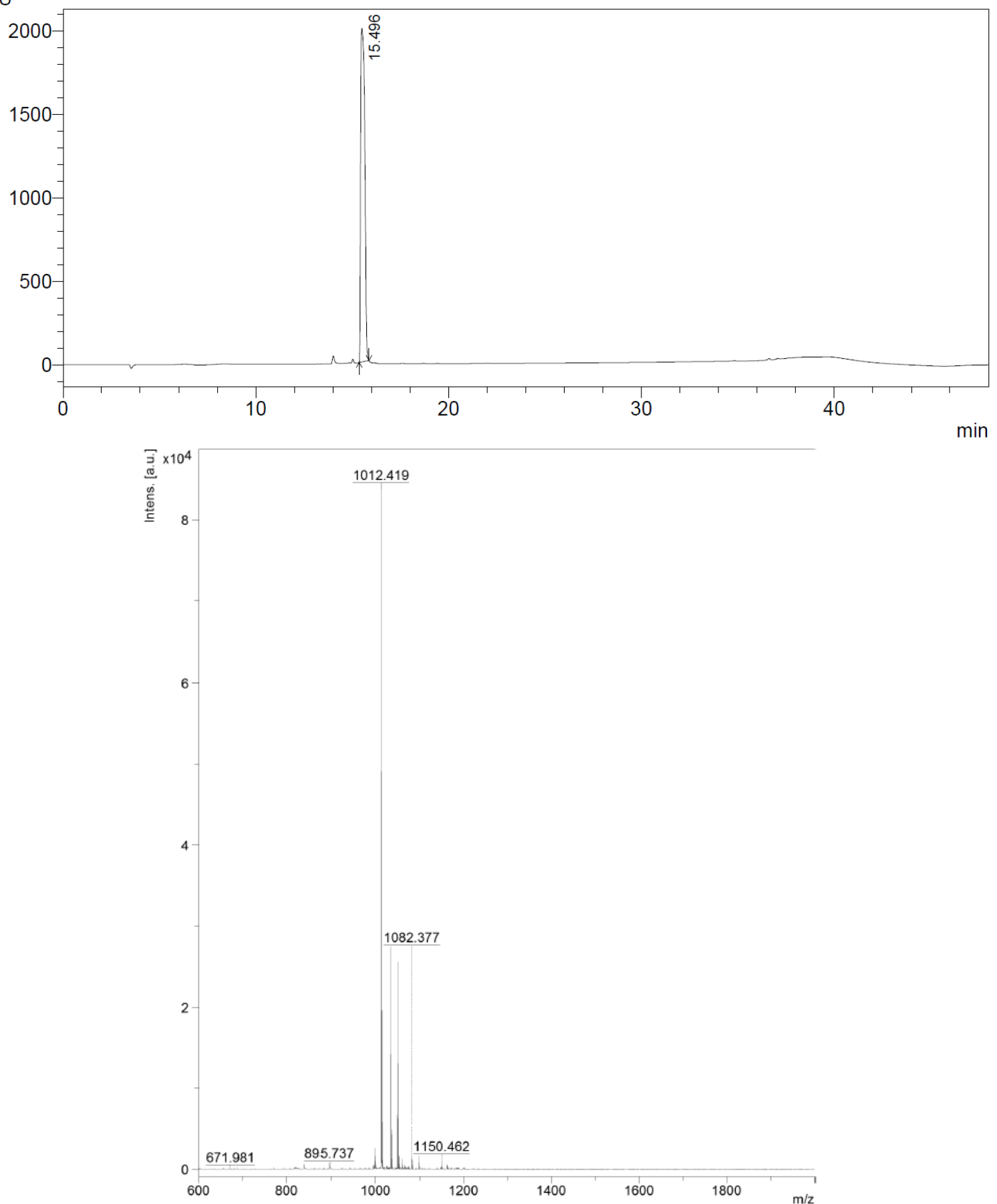
Asn-Gln-Trp-Ala-Val-Gly-His-Leu-Ala-NH2,

$\left[\mathrm{Ala}^{9}\right] \mathrm{BN}^{6-14}$

$[\mathrm{M}+\mathrm{H}]^{+}$calculated 994.125 , found 994.468
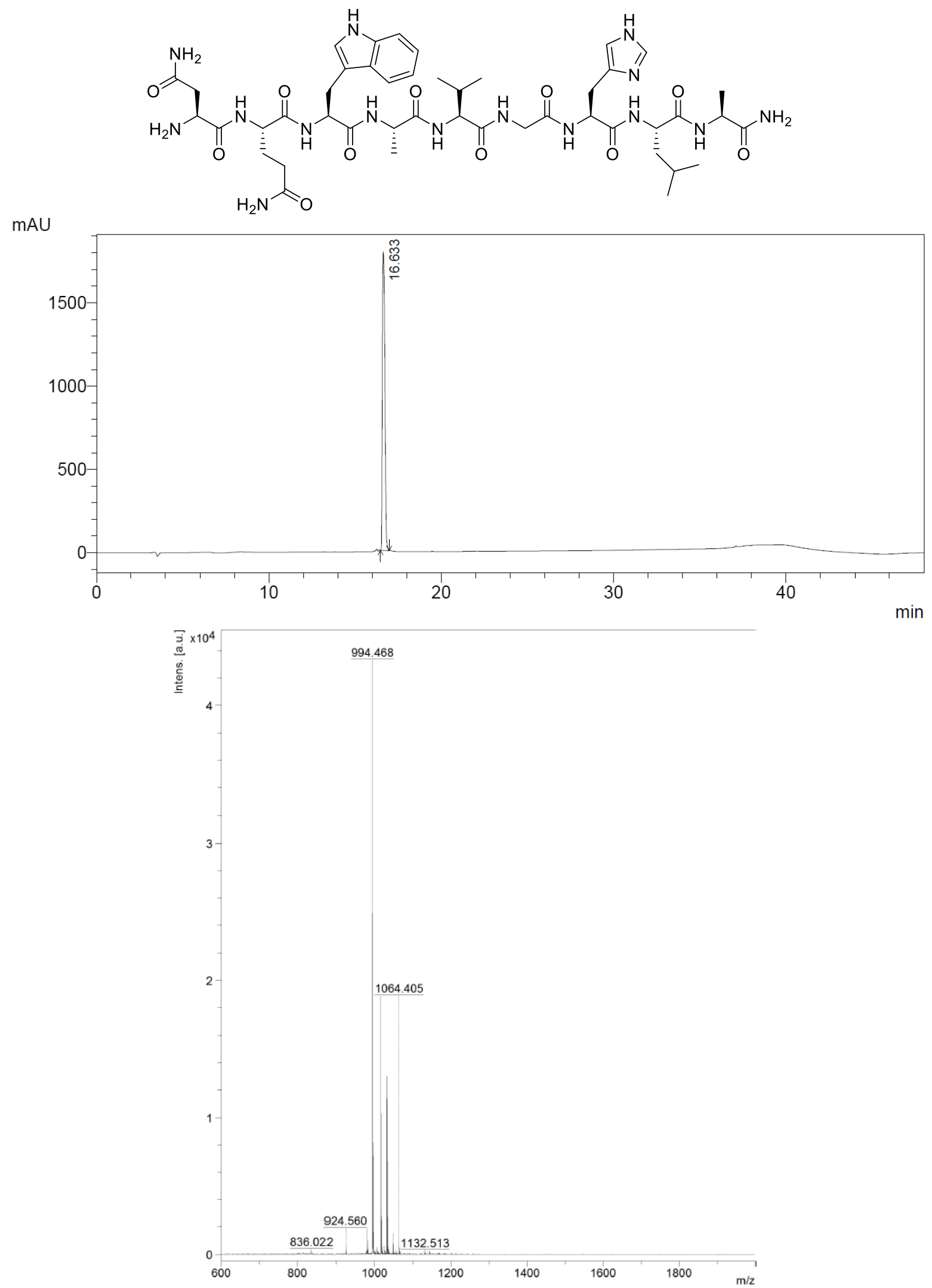